\title{
Identidade, Reconhecimento e Redistribuição: uma análise crítica do pensamento de Charles Taylor, Axel Honneth e Nancy Fraser'
}

Javier Amadeo ${ }^{2}$

\section{Resumo}

A política de identidade e o conceito de reconhecimento têm se transformado em questões dominantes da teoria política contemporânea. Como conceito, o reconhecimento significa que um indivíduo ou grupo social reivindica o direito a ter sua identidade reconhecida, de forma direta ou através da mediação de um conjunto de instituições. As teorias que tem problematizado estas questões abordam tanto temas teóricos importantes como questões políticas centrais do nosso tempo, como a definição de direitos das minorias, reivindicações de autodeterminação nacional ou os desafios colocados por nossas sociedades cada dia mais multiculturais. Dessa forma, o objetivo central do presente artigo é apresentar e discutir os argumentos centrais de Charles Taylor, Axel Honneth e Nancy Fraser que têm se transformando em essenciais para esta discussão, enfatizando o debate em torno da relação entre reconhecimento e redistribuição, e mais especificamente entre o problema da injustiça baseada na questão da identidade e o problema da injustiça econômica. Por último, tentaremos entender algumas das implicações teóricas e políticas do discurso da diferença e das teorias do reconhecimento dentro de uma perspectiva conceptual mais ampla.

Palavras-chave: Identidade. Reconhecimento. Redistribuição. Taylor. Honneth. Fraser.

\section{Introdução}

O conceito de reconhecimento tem se transformado num dos conceitos dominantes da teoria política contemporânea. Como conceito, o reconhecimento significa que um indivíduo ou um grupo social reivindica o direito a ter sua identidade reconhecida, de forma direta ou através da mediaçáo de um conjunto de instituiçóes.

I O presente texto é resultado das discussões realizadas no grupo de pesquisa "Crítica e emancipação" da Unifesp.

2 Universidade Federal de São Paulo (UNIFESP). 
Como afirma Markell, o desenvolvimento do conceito de reconhecimento tem servido como ponto de conexão entre questôes filosóficas mais amplas, como a questáo da identidade, a importância da estima social ou o valor da autorrealização nas sociedades contemporâneas, e problemas políticos concretos, como os desafios do multiculturalismo na educação, os dilemas de uma política sobre a língua oficial em países multilinguísticos, a definição dos direitos dos aborígenes e das minorias sexuais, e as reivindicaçóes de autodeterminação nacional, entre outros (MARKELL, 2008, p. 450).

O interesse nas questóes da identidade e do reconhecimento entre os teóricos políticos adquiriu força - continua Markel - nos anos de 1990 e pode ser entendido como uma reaçáo teórica contra a ênfase colocada na questão da justiça distributiva e contra algumas formulaçóes de caráter mais economicistas que subestimavam as questóes culturais e identitárias. Ao fim da mesma década, alguns dos teóricos envolvidos na discussão começaram a questionar o que podia ser visto com uma ênfase exagerada na questão da diferença, negligenciando o problema da desigualdade material (MARKELL, 2008, p. 451) ${ }^{3}$.

$\mathrm{Na}$ discussão sobre reconhecimento, estão presentes enfoques diversos e perspectivas diferentes. No entanto, é possível identificar alguns textos e questóes-chaves que construíram boa parte das premissas e colocaram questóes fundamentais do debate sobre o tema, ainda que suas perspectivas não sejam completamente convergentes.

O artigo The Politics of Recognition de Charles Taylor, publicado em 1992, é considerado um dos textos fundadores da discussão sobre reconhecimento - junto com o texto de Axel Honneth. Taylor vai propor, como afirma Markell, uma mudança na discussão teórica com relação ao debate liberal-comunitarista da década de 1980. O autor vai sugerir que a discussáo sobre o sistema político e sobre as emendas constitucionais que determinaram a diversidade linguística no Canadá deveriam ser entendidas como exemplos de uma "política de reconhecimento"4. E essa forma de política buscaria transformar a maneira como os cidadãos são considerados socialmente e, ao mesmo tempo, seria um modo de satisfazer uma necessidade humana profunda de

3 Como, por exemplo, o caso de Nancy Fraser como analisaremos a seguir.

4 Conforme Taylor, 2000, p. 260-26I. 
se ser reconhecido como portador de uma identidade distintiva. Para Taylor, o liberalismo seria cego às diferenças e, como consequência, não responderia adequadamente ao desafio colocado pela política de identidade. Uma política de inspiração liberal seria, na interpretação de Taylor, capaz de reconhecer somente aquelas características que pudessem ser universalmente compartilhadas (MARKELL, 2008, p. 451-452).

Axel Honneth apresenta na obra The Struggle of Recognition (2003), também publicada originalmente em 1992, uma leitura diferente da questão do reconhecimento, ainda que certas influências teóricas de autores como Hegel e Mead sejam compartilhadas por Taylor. Para o autor alemão - sustenta Markell - o conceito de reconhecimento deve servir como categoria fundamental para uma reconstrução da tradição da teoria crítica ${ }^{5}$. Na leitura de Honneth, a injustiça social resulta da negaçáo do reconhecimento intersubjetivo, o que perturba de forma violenta a relaçáo do indivíduo com ele mesmo, e isso pode acontecer como resultado da violência física, da recusa à proteçáo legal ou mediante a negativa do reconhecimento individual ou coletivo (MARKELL, 2008, p. 451).

Nancy Fraser publicou, em 1995, dois ensaios que buscavam discutir os conflitos entre a política de reconhecimento e a política de redistribuição (FRASER, 1995a, 1995b). Na luta contra as injustiças sociais, a política de reconhecimento busca reafirmar as identidades sociais, ao tempo que a política de redistribuição busca construir uma perspectiva mais universalista que implique a desapariçáo das diferenças. A resposta de Fraser frente a esse dilema foi introduzir uma distinção transversal entre dois tipos de soluçóes para as injustiças sociais, dependendo se estas são culturais ou econômicas (MARKELL, 2008, p. 456-457).

Os ensaios de Fraser provocaram um intenso debate em torno das questóes problematizadas pela autora. Um dos momentos mais importantes desse debate foi a publicação de Recognition or distribution? A Political-Philosophical Exchange (2003), escrito por Axel Honneth e Nancy Fraser. Para os autores, o que está em questão é entender qual é a relação entre demandas de reconhecimento e de redistribuição. Fraser e Honneth partem, portanto, de um

5 Para uma análise histórica desta tradição teórica, ver o texto clássico de Martin Jay, 2008. 
entendimento comum sobre a necessidade de problematizar a relação entre reconhecimento e redistribuição. No entanto, o tipo de relação construída por cada autor apresentará diferenças teóricas importantes, colocando o debate sobre aspectos de filosofia moral, teoria social e análise política.

Dessa forma, o objetivo central do presente artigo é apresentar e discutir os argumentos centrais de Charles Taylor, Axel Honneth e Nancy Fraser nas obras mencionadas, que têm se transformando em essenciais para esta discussão, enfatizando o debate em torno da relação entre reconhecimento e redistribuição, e - mais especificamente - entre o problema da injustiça baseada na questão da identidade e o problema da injustiça econômica. Por último, tentaremos entender algumas das implicaçóes teóricas e sociais do discurso da diferença e da teoria do reconhecimento com base em um conjunto de críticas formuladas por autores como Judith Butler, Iris Young e Patchen Markell.

\section{A política do reconhecimento}

Como afirmamos na introdução deste estudo, o texto de Charles Taylor The Politics of Recognition, publicado como parte do livro Multiculturalism. Examiningthe Politics of Recognition, pode ser considerado uma das obras fundadoras da teoria do reconhecimento. Taylor, autor canadense, filho de pai anglófono e mãe francófona, é um dos principais teóricos contemporâneos do multiculturalismo. Do ponto de vista político, uma das principais preocupaçóes de Taylor, como claramente se reflete no texto mencionado, é a questáo da identidade dos Que becois no Canadá (KEUCHEYAN, 2013, p. 228).

$\mathrm{Na}$ abertura do texto, Taylor afirma que algumas correntes da política contemporânea

[...] giram em torno da necessidade, por vezes da exigência de reconhecimento. Pode-se dizer que essa necessidade é uma das forças propulsoras dos movimentos políticos nacionalistas. E a exigência vem para o primeiro plano de uma série de maneiras, na política contemporânea, em favor de grupos minoritários ou "subalternos", em algumas modalidades de feminismo e naquilo que se chama política do multiculturalismo [...] a exigência de reconhecimento assume nesses casos caráter de urgência dados os supostos vínculos entre o reconhecimento e identidade, em que 'identidade' designa algo como uma compreensão de quem somos, de nossas características definitórias fundamentais como seres humanos. (2000, p. 24I). 
Para Taylor, a formação das identidades depende do reconhecimento dos outros. Esta visão, sustenta Keucheyan (2013, p. 228-229), parte de uma ontologia intersubjetiva, as identidades não têm existência por si mesmas. Isso implica que, se um indivíduo ou grupo social não é reconhecido pelos outros, a formação da sua identidade ocorrerá em condiçóes desfavoráveis.

Como afirma Taylor,

[...] nossa identidade é moldada em parte pelo reconhecimento ou por sua ausência, frequentemente pelo reconhecimento errôneo por parte dos outros, de modo que uma pessoa ou grupo de pessoas pode sofrer reais danos, uma real distorção, se as pessoas ou sociedades ao redor deles lhes devolverem um quadro de si mesmas redutor, desmerecedor ou desprezível. O não-reconhecimento [sic] ou o reconhecimento errôneo podem causar danos, podem ser uma forma de opressão, aprisionando alguém numa modalidade de ser falsa, distorcida e redutora. (2000, p. 24I, itálico no original).

No argumento do autor canadense, o não reconhecimento é um aspecto fundamental na perpetuação do processo de subordinação social de determinados grupos sociais, por exemplo, no caso da imagem negativa ou depreciativa que as mulheres foram induzidas a ter de si mesmas no interior de sociedades patriarcais. Como parte desse processo de ausência de reconhecimento da sua identidade, as mulheres internalizaram uma visão da sua suposta inferioridade, e esta imagem depreciada tem um papel fundamental na preservação da subordinação da mulher nas sociedades contemporâneas, impossibilitando sua emancipação efetiva, ainda que os obstáculos objetivos de sua emancipação deixassem de existir. Dessa forma, como afirma Taylor, o reconhecimento social é uma necessidade fundamental: "O devido reconhecimento não é uma mera cortesia que devemos conceder às pessoas. É uma necessidade humana vital" (TAYLOR, 2000, p. 241-242).

De acordo com Taylor, a formação das identidades sociais depende do reconhecimento dos outros indivíduos. Como afirma Keucheyan, isso implica que, se determinados grupos sociais não são reconhecidos ou são reconhecidos de maneira errônea, o processo de construçáo da identidade desses grupos e, também, dos indivíduos que formam parte deles ocorrerá de forma inadequada. Os grupos sociais estigmatizados são vítimas de uma opressão de caráter externo que impede o acesso a determinado status social, no entanto, existe também uma opressáo interna que implica que os grupos ou indivíduos têm 
uma imagem depreciada deles mesmos. O reconhecimento, nessa interpretação, é uma característica peculiar das sociedades contemporâneas, em contraste com outras sociedades, da mesma forma que a honra era a característica distintiva da sociedade feudal - distribuída de maneira desigual entre os indivíduos. Para Taylor, o princípio básico da sociedade contemporânea é: a igual dignidade dos individuos (KEUCHEYAN, 2013, p. 229).

$\mathrm{Na}$ interpretação de Taylor, duas mudanças importantes ocorreram para que a questão da identidade e do reconhecimento passassem a ocupar um lugar central nas sociedades modernas.

Em primeiro lugar, afirma Taylor, foi o colapso das hierarquias sociais existentes nas sociedades tradicionais e que tinham na honra seu fundamento. O conceito de honra no antigo regime partia do pressuposto da existência de uma desigualdade intrínseca na constituição daquela estrutura social. Frente a essa noção de honra, surgiu nas sociedades modernas a noçáo de dignidade, construída em um sentido universalista e igualitário - dignidade dos seres humanos como categoria universal. Dessa forma, continua o autor, o conceito de dignidade passou a ser o único conceito compatível com as sociedades democráticas e, como consequência, as formas de reconhecimentos passaram a ser essenciais na cultura democrática moderna. Como afirma Taylor (2000, p. 242-243): "A democracia introduziu uma política de reconhecimento igual que assumiu várias formas ao longo dos anos e que agora voltou na forma de exigência de igual status de culturas e gêneros".

Em segundo lugar, sustenta Taylor, a questão do reconhecimento alcança um novo patamar teórico e político com o surgimento da identidade individual no final do século XVIII. Para o autor, é possível falar de uma identidade individualizada, isto é, uma identidade particular a mim e que vou encontrar em mim mesmo. Neste ponto, Taylor vai retomar a noção de Lionel Trilling (1972), e propor o ideal de "autenticidade", definido como o ideal de "ser fiel a mim mesmo e à minha própria maneira particular de ser" (TAYLOR, 2000, p. 243).

Para compreender a relação profunda entre identidade e reconhecimento, afirma Taylor (2000), devemos considerar uma característica crucial da vida humana, a inclinação fundamentalmente dialógica da experiência humana. Entender esta inclinação dialógica implica entender o 
papel da linguagem no processo de formação dos agentes humanos (TAYLOR, 2000, p. 243).

Para Taylor, a construçáo da minha própria identidade náo pode ser realizada de forma isolada, pelo contrário, deve ser realizada por meio do diálogo com os outros. A identidade socialmente constituída pela sua própria natureza depende da sociedade. $\mathrm{O}$ reconhecimento coletivo estava estruturado em uma identidade socialmente derivada do resultado de uma hierarquia social aceita por todos. No entanto, esse reconhecimento dado como garantido nas sociedades hierárquicas tornou-se um problema com o surgimento das sociedades modernas. Na modernidade, o reconhecimento náo pode mais ser dado como certo (TAYLOR, 2000, p. 248).

O reconhecimento passou a ter, portanto, um papel cada vez mais importante nas sociedades contemporâneas, tanto no plano íntimo como no plano social. No argumento de Taylor (2000), ambos os planos foram moldados pelo ideal de autenticidade e o reconhecimento passou a desempenhar um papel fundamental na sociedade que se construiu com base nesse ideal. Do ponto de vista social, a importância do diálogo aberto no processo de construçáo das identidades colocou a política do reconhecimento no centro da discussão no espaço público.

Como afirma Taylor (2000, p. 249-250):

Assim, o discurso do reconhecimento tornou-se familiar a nós em dois níveis. Em primeiro lugar, na esfera íntima, em que compreendemos que a formação da identidade e do Self ocorre num contínuo diálogo e luta com outros significativos. E, em segundo lugar, na esfera pública, onde uma política de reconhecimento igual veio a desempenhar um papel cada vez mais importante. ${ }^{6}$

O reconhecimento passou a ter um papel central nas sociedades democráticas e o não reconhecimento ou o reconhecimento errôneo passou a infringir danos significativos naqueles grupos sociais afetados. Correntes do feminismo, grupos em defesa dos direitos das minorias e do multiculturalismo têm como posição política comum a visão de que o não reconhecimento deve ser considerado uma forma de opressão social (TAYLOR, 2000, p. 249).

6 Sobre esta questão ver: Taylor, 1997. 
O processo descrito por Taylor teve importantes consequências do ponto de vista do seu impacto na esfera pública. O surgimento da noção de dignidade esteve acompanhado de uma política universalista que colocou a ideia de uma dignidade igual para todos os cidadáos, passando, assim, de uma ideia de privilégios para uma ideia universalista de direitos. Como consequência, chegamos à ideia moderna de cidadania como gozo de direitos universais. Em contrapartida, afirma Taylor (2000, p. 250), surge a política de diferença como resultado do desenvolvimento da moderna ideia de identidade. Assim, todos os grupos e indivíduos devem ter o direito ao reconhecimento da sua identidade.

Na leitura de Taylor, a política da dignidade parte do pressuposto de um ser universal com o mesmo conjunto de direitos e obrigaçóes. Por sua vez, a política da diferença parte do reconhecimento de uma identidade particular de um grupo ou indivíduo, aquilo que o faz diferente dos outros (TAYLOR, 2000, p. 250).

Como afirma Taylor:

Conflitos semelhantes advêm hoje em torno da política da diferença. Onde a política da dignidade universal lutava por formas de não discriminação que fossem deveras "cegas" às maneiras pelas quais os cidadãos diferem, a política da diferença redefine com freqüência [sic] a não discriminação como algo que requer que façamos dessas distinções a base do tratamento diferenciado (TAYLOR, 2000, p. 25I).

A política da diferença critica o suposto universalismo da política da dignidade por considerar ser uma imposição de um conjunto de valores dominantes disfarçados na ideia de valores universais. $\mathrm{O}$ desafio teórico e político para Taylor é conciliar ambos os princípios: política de dignidade e política de diferença, universalismo e particularismo. Para conciliar estes princípios seria necessário o reconhecimento daquilo que está universalmente presente em todos - uma identidade - por meio do reconhecimento do que há de particular em cada um. Assim, para Taylor (2000, p. 251), a exigência universal "fortalece um reconhecimento da especificidade".

Do ponto de vista político, Taylor vai defender um tipo de liberalismo que defenda um conjunto de direitos fundamentais e pressupostos de tratamento igualitário, mas que, ao mesmo tempo, seja capaz de distinguir a 
importância de certas formas de tradição cultural e de propor um conjunto de direitos específicos para sua preservação ${ }^{7}$. Para o autor canadense, cada vez mais as sociedades de hoje são multiculturais, no sentido de incorporar vários grupos sociais ou comunidades culturais. Portanto, um liberalismo procedimental e completamente cego às diferenças seria impraticável nas nossas sociedades contemporâneas ${ }^{8}$. Seria desejável um tipo de liberalismo mais tolerante, que seja capaz de evitar a simples homogeneização da diferença e que seja mais adequado às sociedades multiculturais da atualidade (TAYLOR, 2000, p. 266-267).

\section{Reconhecimento e redistribuição: Fraser versus Honneth}

A teoria do reconhecimento proposta por Taylor tem colocado vários temas em questáo. Um dos principais temas em aberto se refere à relaçáo entre as demandas de reconhecimento ou de tipo cultural e as demandas de redistribuição ou de tipo econômico. Essa tensão entre diferentes tipos de demanda tem sido objeto de debate entre dois dos principais representantes da teoria do reconhecimento, Nancy Fraser e Axel Honneth. Tal debate foi plasmado no livro Redistribution or recognition. A political-philosophical Exchange, de 2003. No texto, os autores examinam a relação entre a redistribuição, que designa as desigualdades de caráter material, e o reconhecimento referente às desigualdades de identidade ou de status (KEUCHEYAN, 2013, p. 229).

Os autores partem do pressuposto de que as lutas pela identidade têm proliferado de maneira crescente a partir da década de 1970. No sentido contrário, argumentam Fraser e Honneth (2003), as lutas de caráter econômico, que foram dominantes durante grande parte da modernidade, têm sofrido retrocessos e perdido legitimidade como principal demanda social. Um conjunto de razóes parece explicar essa importante mudança nas lutas dos movimentos contestatários. Em primeiro lugar, a crescente complexidade da sociedade moderna tem criado demandas de reconhecimento entre diferentes

7 O caso das reinvindicações feitas pelos canadenses franceses e pelos povos aborígenes no Canadá para a preservação de suas identidades são os exemplos que têm influenciado o pensamento de Taylor nessa discussão sobre preservação cultural e direito de reconhecimento. Ver: Taylor, 2000, p. 260-267.

8 Ao falar de liberalismo procedimental, Taylor está se referindo ao liberalismo defendido por autores como John Rawls (1985, 2008) Ronald Dworkin (2007) e Bruce Ackerman (1980). 
grupos sociais. Em segundo, a existência de um mundo cada vez mais interconectado tem levado a uma crescente hibridização e, ao mesmo tempo, a uma percepção das diferenças culturais entre grupos e indivíduos (KEUCHEYAN, 2013, p. 229).

Se o reconhecimento tem se transformado em um dos conceitos-chave da teoria política contemporânea, isso não significa que a questão da redistribuição tenha desaparecido completamente do horizonte teórico, as desigualdades econômicas continuam presentes na sociedade contemporânea e a teoria política e social deve continuar teorizando sobre seus fundamentos e soluçóes.

Para Fraser e Honneth, o que está em questão é, como aparece no título do livro, entender qual é a relação entre demandas de reconhecimento e de redistribuição. Os autores partem de uma premissa compartilhada de que, para um entendimento adequado de uma concepção de justiça, é necessário levar em consideraçáo dois conjuntos de preocupaçóes: aquelas ligadas às lutas pela distribuição dos bens econômicos e aquelas vinculadas às lutas pelo reconhecimento. Fraser e Honneth também compartilham outro pressuposto importante, a recusa às leituras teóricas economicistas que reduzem o reconhecimento a simples epifenômeno da questão distributiva (FRASER; HONNETH, 2003, p. 2).

Fraser e Honneth (2003) partem, portanto, de um entendimento em comum sobre a necessidade de problematizar a relaçáo entre reconhecimento e redistribuição. No entanto, o tipo de relação construído por cada autor terá diferenças teóricas importantes, colocando o debate sobre aspectos de filosofia moral, teoria social e análise política.

Para Honneth, o conceito de reconhecimento é o conceito moral e político fundamental e a redistribuição deve ser pensada como uma categoria derivativa da anterior. Dessa forma, o ideal socialista da redistribuição estaria, na interpretação do autor alemão, subordinado à luta pelo reconhecimento. Fraser, por sua vez, recusa a ideia de que a redistribuição possa ser subsumida na luta pelo reconhecimento. Essa autora norte-americana vai propor uma "perspectiva dualista" de análise que coloque as duas categorias como dimensóes de justiça fundamentais e mutuamente irredutíveis (FRASER; HONNETH, 2003, p. 3). 
A perspectiva teórica colocada por Fraser parte da crítica das vertentes economicistas que dominaram grande parte das reivindicaçóes do movimento operário. No entanto, para a autora também é necessário fazer uma crítica da perspectiva culturalista presente em teorias que defendem as reivindicaçóes identitárias, como nas obras de Taylor e Honneth. Nessa perspectiva, o fato de terem surgido movimentos que lutam pelas suas identidades não significa que as desigualdades econômicas e sociais tenham sido superadas. Pelo contrário, elas parecem ter se acentuado. Fraser, portanto, vai defender uma perspectiva dualista. Para a autora, uma das características fundamentais do capitalismo seria a separaçáo entre as duas formas de hierarquia. No entanto, essa separação não seria absoluta, a opressão econômica reforçaria a opressão cultural e vice-versa, as duas variáveis operariam de forma independente, mas articulada. O desafio, portanto, é elaborar uma teoria que descreva de forma adequada a articulação específica entre distintas formas de opressão social (KEUCHEYAN, 2013, p. 229).

\section{Redistribuição e reconhecimento: uma perspectiva dualista}

\section{da justiça}

Para Fraser, a questão central da teoria política contemporânea é como problematizar o tema da justiça social em um mundo atravessado pela política de identidade. Para a autora, as reivindicaçóes de justiça estáo divididas em dois tipos de exigências. Em primeiro lugar, as exigências redistributivas, que procuram uma distribuição de recursos e riqueza mais justa. Este paradigma reivindicativo de redistribuição igualitária tem, no argumento da autora, dominado a discussão teórica sobre justiça social nos últimos 150 anos. No entanto, nos últimos tempos, uma segunda reivindicaçáo de justiça social tem aparecido com força, a exigência por "políticas de reconhecimento". O objetivo deste tipo de exigência é a demanda por um mundo que aceite a diferença como constitutiva do ser humano e onde a assimilaçáo a padróes culturais dominantes não seja requisito para um tratamento de igual respeito. Para Fraser (2003a, p. 7), este tipo de reivindicaçáo coloca um novo desafio teórico: o desenvolvimento de um novo paradigma de justiça que coloque a questáo do reconhecimento como elemento central.

Em muitos casos, sustenta Fraser, as demandas de redistribuição e de reconhecimento têm estado dissociadas umas das outras. Dentro das estratégias 
construídas pelos movimentos sociais, como o movimento feminista, a reivindicação de uma política de redistribuição como forma de superar a dominação masculina aparece em muitos casos como uma estratégia dissociada de uma reinvindicação que reconheça a diferença de gênero. Para Fraser, esse tipo de exemplo mostra uma tendência mais geral que consiste na separaçáo da política de diferença e da política de igualdade. A perspectiva teórica proposta por Fraser busca conciliar redistribuição com reconhecimento ou política de classe com política de identidade. Como afirma a autora:

It is my general thesis that justice today requires both redistribution and recognition. Neither alone is sufficient. As soon one embrace this thesis, however, the question of how to combinethen becomes paramount. I shall argue that the emancipatory aspects of the two problematic should be integrated in a single comprehensive framework. (FRASER, 2003a, p. 9).

Para Fraser, as questôes de subordinação social em geral implicam tanto problemas de redistribuição como problemas de reconhecimento, e em muitos casos têm se construído uma falsa dicotomia com relação a esta questão. Do ponto de vista teórico, afirma a autora, o desafio é desenvolver uma concepção de justiça que permita articular as reivindicaçôes de igualdade social com as reivindicaçóes do reconhecimento da diferença. Do ponto de vista político, o desafio é conceber um conjunto de políticas e arranjos institucionais que integrem o melhor da política de redistribuiçáo com o melhor da política de diferença (FRASER, 2003a, p. 9).

Assim, as questóes de injustiça na sociedade contemporânea estariam, para Fraser, enraizadas tanto na estrutura econômica como na ordem de $s t a-$ tus social. Os grupos subordinados sofrem de problemas de distribuiçáa e também de problemas de reconhecimento em formas que, afirma a autora, nenhuma das injustiças têm um efeito indireto sobre o outro, mas ambos os problemas sáo primários e co-originais. Fraser vai explorar essa questão analisando o tipo de subordinaçáa colocada pelas injustiças de gênero

Do ponto de vista da questáo distributiva, afirma Fraser (2003a), o gênero funciona como princípio de organização básico da estrutura econômica da sociedade capitalista. Essa estrutura determina uma divisão econômica entre trabalho "produtivo" pago e trabalho "reprodutivo" não pago. Essa estrutura define, também, uma hierarquia no interior do trabalho pago entre altos salários para ocupaçôes profissionais dominadas por homens e baixos salários 
para trabalhos domésticos ocupados por mulheres. Para Fraser (2003a, p. 20), o resultado é uma estrutura econômica que gera formas de injustiça distributiva, incluindo exploração, marginação econômica e privaçôes, especificamente construídas pela questão de gênero.

Do ponto de vista da questáo do reconhecimento, o gênero codifica padróes culturais de interpretação que são centrais para a estrutura social organizada com base no status. Para Fraser, a característica dominante da injustiça de gênero é o androcentrismo: um padráo institucionalizado de valores culturais que privilegia traços associados com a masculinidade, ao tempo que desvaloriza qualquer caraterística associada com a "feminidade". Como resultado, a mulher sofre formas específicas de subordinação de status vinculadas à questão de gênero: agressão sexual e violência doméstica, degradação simbólica vinculada à construçáo de estereótipos, exclusão da esfera pública e negaçáo dos direitos plenos de cidadania. Essas injustiças estáo, para a autora, vinculadas à questão do reconhecimento (FRASER, 2003a, p. 19).

O gênero é - na análise de Fraser - um claro exemplo de um tipo de subordinação social que apresenta duas dimensóes. Não é simplesmente uma questão de classe ou meramente uma questão de status, o gênero é "[...] uma categoria hibrida enraizada simultaneamente na estrutura econômica e na ordem de status da sociedade". Como consequência da dupla dimensão da subordinação, entender e superar as injustiças de gênero implica considerar tanto a dimensão da distribuição como a do reconhecimento (FRASER, 2003a, p. 19) $)^{9}$.

Para a autora, praticamente todas as formas de subordinação presentes nas sociedades contemporâneas podem ser tratadas desde essa perspectiva. O desafio teórico é integrar redistribuição e reconhecimento em um paradigma compreensivo único:

Afirma Fraser (2003a, p. 35):

Instead of endorsing either one of those paradigms to the exclusion of the other, I propose to develop what I shall call a "two-dimensional" conception of justice. A two-dimensional conception treats distribution and a recognition as distinct perspectives on, and dimension of, justice. Without reducing either dimension to the other, it encompasses both of them with a broader overarching framework.

9 A raça seria, também, um exemplo de uma questão que envolve injustiças de distribuição e de reconhecimento. 
No núcleo normativo dessa concepção defendida por Fraser está a noção de paridade participativa ${ }^{10}$. Para Fraser, de acordo com este núcleo normativo, a justiça requer arranjos sociais que possibilitem que todos os cidadáos interajam enquanto indivíduos iguais. Dessa forma, o funcionamento da paridade participativa depende de duas condiçóes. Uma primeira condição se refere à distribuição de recursos materiais, que devem ser distribuídos de maneira que assegurem aos participantes autonomia pessoal. Fraser chama essa condiçáo de condição objetiva da paridade participativa. Uma segunda condição, colocada por Fraser (2003a, p. 35), refere-se à necessidade de padróes culturais institucionalizados que "[...] expressem igual respeito por todos os participantes e que assegure igualdade de oportunidades para alcançar a estima social”. E essa condição será chamada pela autora norte-americana de condição intersubjetiva da paridade participativa (FRASER, 2003a, p. 35).

Tanto a condição objetiva como a condição intersubjetiva são, para Fraser, fundamentais para o funcionamento da paridade participativa. A condiçáo objetiva traz questóes conectadas com a estrutura econômica da sociedade e com as diferenças de classe definidas do ponto de vista econômico; desta forma, a condição objetiva está relacionada com questôes de justiça distributiva. Já a condição intersubjetiva coloca elementos que pertencem à ordem de status ou das hierarquias sociais construídas culturalmente; assim, essa condição foca em preocupaçóes problematizadas pela política de diferença. A proposta de uma concepção de justiça que assuma duas dimensóes e que se oriente pela paridade participativa deve, na visão de Fraser, incorporar questóes de reconhecimento e de redistribuição, aceitando a importância de ambas as reivindicaçóes (FRASER, 2003a, p. 35-36).

Como afirma Fraser (2003a, p. 37):

By construing redistribution and recognition as two mutually irreducible dimensions of justice, it broadens the usual understanding of justice to encompass intersubjetive as well as objective considerations. By submitting both dimensions to the overarching norm of participatory parity, moreover, it brings both within the purview of a single normative framework.

Do ponto de vista político, um elemento essencial da proposta elaborada por Fraser está relacionado com a construção de uma estratégia política de

10 Sobre a utilização desse conceito, ver: Fraser, 1997. 
reformas institucionais que consiga eliminar ou mitigar as injustiças de status e as desigualdades de classe de forma simultânea.

Para Fraser, do ponto de vista das reivindicaçóes de redistribuição, a estratégia de reformas institucionais implica promover uma mudança na estrutura econômica que assegure as condiçóes objetivas da paridade participativa. Do ponto de vista das reivindicações de reconhecimento, o objetivo é remover os impedimentos culturais e elaborar políticas que permitam construir os pré-requisitos intersubjetivos da paridade participativa. Uma consideração final, assinalada por Fraser, se refere à necessidade de aprofundar o processo de democratização da sociedade como forma de eliminar a exclusão e marginalização política (FRASER, 2003a, p. 72).

Essa estratégia de mudanças institucionais deve ocupar um lugar central em uma teoria da justiça que incorpore as reivindicaçôes de redistribuição e de reconhecimento. Para Fraser, é possível construir duas alternativas para avançar na eliminação das injustiças sociais: uma estratégia de afirmação e uma de transformação.

É possível diferenciar, do ponto de vista conceitual, tais estratégias da seguinte forma. Uma estratégia de afirmação busca corrigir as injustiças decorrentes dos arranjos sociais sem alterara estrutura social subjacente que as têm gerado. Uma estratégia de transformação, em contraposição, tem como objetivo corrigir as injustiças sociais propondo uma reestruturaçáo ou transformação das estruturas sociais que deram origem a essas injustiças" ${ }^{\prime \prime}$.

Para Fraser, é possível distinguir essas estratégias tendo como objetivo a construção de uma justiça distributiva. Com base nessa perspectiva, um

$1 /$ Ainda que Fraser explicitamente (2003a, p. 74) rejeite a comparação entre as estratégias por ela propostas e a discussão clássica sobre reforma e revolução, parecem existir claramente pontos de contato importantes que poderiam ser explorados de maneira mais sistemática. Cabe ressaltar que vários autores têm colocado essa distinção não como uma dicotomia e sim como estratégias que devem ser pensadas como complementares. Um exemplo desta posição é o texto clássico de Rosa Luxemburgo Reforma ou revolução?. Como afirma a autora polonesa: "[...] Poderia a social-democracia ser contra a reforma social? [...]. Certamente não. Para a social-democracia, a luta prática cotidiana por reformas sociais, pela melhoria da condição do povo trabalhador dentro da ordem social existente, em favor das instituições democráticas, constitui, pelo contrário, o único caminho capaz de guiar a luta de classe proletária e de trabalhar rumo ao objetivo final, à tomada do poder político e à superação do trabalho assalariado. Para a social-democracia, há um nexo inseparável entre a reforma social e a revolução social, na medida em que a luta pela reforma social é um meio, enquanto a transformação social é um fim" (LUXEMBURGO, 20II, p. I-2, itálico no original). 
exemplo de estratégia afirmativa é a distribuição de renda promovida pelo Estado de bem-estar social, cujo objetivo é dar assistência pública como forma de melhorar a distribuição de renda dos setores mais vulneráveis, mas deixando intata a estrutura econômica da sociedade. Uma estratégia de transformação implica transformar as estruturas econômicas subjacentes; modificar a divisão do trabalho, alterar a distribuição de renda e questionar as formas de propriedade existentes (FRASER, 2003a, p. 74).

O contraste entre as estratégias de afirmação e de transformação também é válido para as políticas de reconhecimento. Um exemplo de estratégia afirmativa nas políticas de reconhecimento, como afirma Fraser, está relacionado com uma visáo do multiculturalismo que propóe reparar o desrespeito mediante a valorização das identidades injustamente desvalorizadas, no entanto sem questionar a própria constituição dessas identidades. Em contraste, uma estratégia de transformação implica um processo de desconstrução, isto é, buscar descontruir as identidades estabelecidas pelos padróes culturais dominantes (FRASER, 2003a, p. 75). Um exemplo desta proposta - de forma desuperar o heterosexismo - pode ilustrar de forma mais clara as propostas alternativas. Uma alternativa é a politica de identidade gay, que valorize a sexualidade gay e lésbica. Outra possibilidade é a política "queer" que propóe uma desconstrução da oposição binária entre homossexualidade e heterossexualidade (FRASER, 2003a, p. 75) ${ }^{12}$.

No entanto, a distinção entre estratégias de afirmação e de transformação é contextual e não absoluta. É possível - no argumento de Fraser - pensar uma estratégia que proponha "reformas não reformistas". Isto é, políticas que tenham uma fase dupla: por um lado, permitiriam afirmar as identidades dos indivíduos e satisfazer as reivindicaçóes de distribuição e reconhecimento dentro das estruturas existentes; por outro lado, essas reformas colocariam em ação mudanças que permitiriam que novas transformaçóes ainda mais radicais fossem possíveis em momentos subsequentes. Para Fraser, se a estratégia de reformas náo reformistas for bem-sucedida, as transformaçóes alcançadas podem ir além das mudanças institucionais especificamente propostas e inclusive mudar o terreno político no qual serão realizadas as lutas futuras. Mudando a estrutura de incentivos e a estrutura de oportunidades políticas, afirma a

12 Sobre a proposta da política "queer" ver, entre outros: Butler, 2014. Sobre a teoria queer ver, também: Salih, 20I2. 
autora, é possível expandir as opçóes políticas para futuras reformas. Os efeitos cumulativos das reformas podem transformar as estruturas sociais profundas que geram injustiças na sociedade atual (FRASER, 2003a, p. 79-80).

Como afirma Fraser:

Whatever this orientation, non-reformist reforms seek to spark transformation in the status order - not only directly, by immediate institutional intervention, but also politically, by changing the terrain on which future struggles for recognition are waged. Thus, for recognition as form distribution, this approach represents a via media between affirmation and transformation that combines the best features of both. (2003a, p. 82).

\section{Redistribuição como reconhecimento: por uma teoria crítica compreensiva $^{13}$}

Honneth discorda de alguns pressupostos da proposta teórica apresentada por Fraser. No argumento desenvolvido por Fraser, segundo a interpretaçáo de autor alemão, os objetivos normativos da teoria crítica seriam concebidos como resultado de uma síntese de consideraçóes de justiça "material" e "cultural" (HONNETH, 2003b, p. 113).

A perspectiva de Honneth é, neste ponto, diferente, como afirma o autor:

My thesis is that an attempt torenew the comprehensive claims of Critical Theory under present conditions does better to orient itself by the categorial framework of a sufficiently differentiated theory of recognition, since this establishes a link between social causes of widespread feeling of injustice and the normative objectives of emancipatory movements. (2003b, p. 1 13).

Vários temas importantes aparecem no debate entre Fraser e Honneth, questóes de caráter normativo, visóes sobre a dominaçáo social no capitalismo e sobre o vínculo entre movimentos sociais e teoria crítica, para mencionar apenas alguns. No entanto, as diferentes questôes parecem convergir em torno de uma discussão mais geral sobre quais são as categorias analíticas mais adequadas para entender às reinvindicaçóes normativas dos movimentos sociais de forma articulada (HONNETH, 2003b, p. 113).

13 Retomamos o título do capítulo publicado pelo autor na obra conjunto com Fraser. Consultar: Fraser $e$ Honneth, 2003. 
Na perspectiva de Honneth, inclusive as injustiças de caráter distributivas devem ser entendidas como expressão institucional de desrespeito social ou como expressão de relações de reconhecimento injustificadas. Para o autor alemão, a dicotomia entre "redistribuição" e "reconhecimento", proposta por Fraser, deve ser questionada; o problema decisivo a ser colocado é a justificativa normativa das demandas de reconhecimento. Para elaborar uma crítica adequada das injustiças contemporâneas, em termos da teoria do reconhecimento, afirma Honneth, é decisivo partir do pressuposto da existência de concepçáo de boa vida e não somente pressupostos de caráter procedimental (HONNETH, 2003b, p. 114).

Para Honneth, existem alguns equívocos nos pressupostos teóricos colocados por Fraser que têm consequências importantes na construção analítica desenvolvida pela autora norte-americana. Para o autor, um dos principais méritos dos pensadores da teoria crítica foi ter procurado fundamentos empíricos para entender a relevância dos conflitos nas sociedades contemporâneas. Dessa forma, afirma Honneth (2003b), um dos pressupostos a serem questionados é se o descontentamento moral articulado pelos "novos" movimentos sociais seria válido como problema conceitual fundamental da elaboração teórica. Esse seria, para o autor alemáo, um dos equívocos de Fraser - para quem a legitimidade do quadro normativo da teoria crítica deveria ser analisada pela sua capacidade de expressar os objetivos políticos dos movimentos sociais. Para Honneth, "[...] a introdução dos conceptos normativos centrais em uma teoria social crítica não deve ser determinada diretamente pela orientação para os 'movimentos sociais'” (HONNETH, 2003b, p. 117).

Para Honneth (2003b, p. 117), Fraser realiza uma leitura reducionista da política contemporânea ao analisar as características da era pós-socialista a partir da perspectiva colocada por certo tipo de movimento social. As sociedades contemporâneas apresentariam grande quantidade de grupos politicamente organizados com o objetivo de atingir o reconhecimento da sociedade. No entanto, a análise desenvolvida por Fraser centra seu diagnóstico no processo de resistência ao desrespeito e à marginalização sofridos por movimentos de mulheres, grupos étnicos e minorias sexuais presentes em países desenvolvidos, e que seriam resultado de uma estrutura social construída com base em padróes de cidadania de indivíduos masculinos, brancos e heterossexuais. 
A luta destes grupos teria como objetivo mudar a cultura do país, eliminando os estereótipos sociais e buscando o reconhecimento das diversas tradiçóes e formas de vida. O problema dessa perspectiva, afirma Honneth, é a generalizaçáo excessiva da experiência norte-americana; em outros países, como França, Alemanha e Inglaterra, as lutas sociais pela "política da identidade" ocupam um lugar subordinado a problemas considerados "tradicionais": o estado de bem-estar, os direitos trabalhistas ou as questóes ecológicas, temas mais importantes na esfera pública desses países. Para Honneth (2003b, p. 117-118), além da questáo da generalizaçáo de uma experiência social de caráter mais particular, há outra questão fundamental a ser problematizada: “[...] quais são as formas moralmente relevantes de sofrimento e privação social que devemos analisar e construir teoricamente para chegar ao diagnóstico de que hoje estamos enfrentando essencialmente lutas por 'reconhecimento' cultural?".

Retomando as objeçóes colocadas por Bourdieu, Honneth (2003b) questiona o cenário pós-socialista de conflito social construído por Fraser. Para o autor alemão, existe nas sociedades contemporâneas uma quantidade extraordinária de lutas cotidianas, no entanto, somente uma parte relativamente pequena pode ser colocada sob o rótulo de luta pelo reconhecimento no sentido construído pelos "novos" movimentos sociais. Essa crítica de Bourdieu colocaria em discussão a noção errônea de que o desenvolvimento das sociedades capitalistas é marcado fundamentalmente por conflitos sociais resultados de demandas de reconhecimento cultural. A consequência normativa de considerar apenas os objetivos colocados por essas demandas no esquema conceitual da teoria crítica, afirma Honneth, é que as demandas distributivas dos movimentos sociais marginalizados somente poderão ser incorporadas em um segundo momento na estrutura conceitual da teoria. Para Honneth, o erro essencial dessa perspectiva proposta por Fraser está na premissa inicial que sustenta que os movimentos sociais devem servir de guia empírico de problemas normativos relevantes do ponto de vista social (HONNETH, 2003b, p. 120).

Para Honneth, é necessário o desenvolvimento de uma teoria crítica da sociedade que retome a teoria do reconhecimento de Hegel, e de outros autores contemporâneos $^{14}$, cuja premissa principal a ser resgatada e aprofundada do

14 Em especial, autores como Tzuetan Todorov, Avishai Margalit e Michael Ignatieff. 
ponto de vista teórico é a de que a experiência da retirada do reconhecimento social deve ser colocada no centro "de um conceito significativo de sofrimento e injustiça socialmente determinados". Esses autores, afirma Honneth, têm contribuído para a elaboração de uma teoria social normativamente substantiva com base na seguinte ideia: os conceitos básicos através dos quais a injustiça social serve de fundamento para uma teoria da sociedade devem ter como pressuposto as expectativas normativas dos sujeitos com vistas ao reconhecimento social da sua integridade pessoal (HONNETH, 2003b, p. 120).

Nesse ponto, aparecem diferenças substantivas com a proposta colocada por Fraser. Para Honneth, o quadro conceitual do reconhecimento é de fundamental importância nos dias atuais. No entanto, essa centralidade não seria resultado da emergência de "novos" movimentos sociais com reivindicaçóes de reconhecimento. Para o autor alemão, a teoria do reconhecimento é fundamental porque esta tem demonstrado ser a ferramenta teórica apropriada para dar conta analiticamente da experiência social de injustiça nas sociedades contemporâneas. Não seria, portanto, uma nova ideia de opressão coletiva caracterizada em termos de diferença ou de reconhecimento cultural, o que serviria como fundamento normativo para a teoria do reconhecimento. A importância do quadro conceitual do reconhecimento está, no argumento colocado por Honneth, nas fontes morais da experiência de descontentamento social (HONNETH, 2003b, p. 133).

Para Honneth (2003b, p. 135) assevera que

"[...] it seems highly implausible to me to interpret the history of political conflict within capitalist societies according to schema that asserts a transition from interest-based to identity-oriented social movements, and hence a shift in normative semantics from "interest" to "identity" or from "equality" to "difference".

Existiram previamente ao período colocado por Fraser e também por Taylor formas de protesto social e descontentamento moral, nas quais a linguagem de desrespeito e da falta de reconhecimento teve um rol semântico central. Honneth (2003b) menciona que o vocabulário moral utilizado no final do século XIX e começo do século XX por trabalhadores, grupos de mulheres emancipadas e movimentos afro-americanos permitia que articulassem seus protestos denunciando o desrespeito e a humilhação social a que eram submetidos seus membros. Seria possível entender as experiências de 
injustiça, continua o autor, concebidas como um contínuo de formas de não reconhecimento ou desrespeito, cujas diferenças estariam determinadas por aquelas capacidades ou características que foram injustamente não reconhecidas ou desrespeitadas. Segundo o autor, essa perspectiva busca eliminar uma distinção rígida, ou dicotômica, entre redistribuição e reconhecimento, e procura avançar no desenvolvimento de ferramentas conceituais mais adequadas para entenderas lutas pelo reconhecimento nas sociedades contemporâneas (HONNETH, 2003b, p. 135-136).

Honneth aduz que, como resultado do processo de desenvolvimento moral e social da sociedade burguesa-capitalista, é possível diferenciar três esferas de reconhecimento. $\mathrm{O}$ processo de transformação social estabeleceu formas distintas de relacionamento social no qual os indivíduos podem contar com o reconhecimento recíproco em formas variadas e de acordo com princípios diferentes. O surgimento do indivíduo, afirma Honneth, produziu uma revolução na ordem do reconhecimento; como consequência, o sujeito na sociedade burguesa-capitalista refere-se a si em três atitudes diferentes: nas relaçóes íntimas, caracterizadas por práticas de cuidado e afeto mútuo, ele se percebe como indivíduo com suas próprias necessidades; nas relaçóes legais, que se desenvolvem de acordo com o modelo de iguais direitos mutuamente garantidos, ele se entende como pessoa jurídica possuidora de igual autonomia; e, finalmente, nas relaçóes sociais, dominadas por um modelo competitivo por status profissional, nas quais se percebe como possuindo habilidades e talentos valiosos para a sociedade (HONNETH, 2003b, p. 142).

Honneth (2003b, p. 143) acrescenta que a diferenciaçáo em diferentes esferas de reconhecimento tem consequências normativas importantes:

[...] each of the tree forms of relation I have outlined is distinguished by the internal normative principles that established different forms of mutual recognition. "Love" (the central idea of intimate relationship), the equality principle (the norm of legal relation), and the achievement principle (the standard of social hierarchy) represent normative perspectives with reference to which subjects can reasonably argue that existing forms of recognition are inadequate or insufficient and need to be expanded.

Como resultado dos argumentos teóricos construídos para entender o desenvolvimento moral e social da sociedade burguesa-capitalista, Honneth chega à conclusão de que uma concepção adequada da ordem social 
contemporânea requer náo somente incluir as três esferas de reconhecimento social - e como consequência as expectativas que os indivíduos possuem de reconhecimento recíproco - mas também, continua o autor, considerar os valores culturais envolvidos na constituição da esfera econômica através da interpretação do princípio de autorrealização. Para o autor alemão, as instituições centrais da sociedade capitalista requerem legitimação racional através de princípios generalizáveis de reconhecimento recíproco. A reprodução do sistema social depende, assim, de uma base de consenso moral - como mecanismo de integraçáo social primordial e base das expectativas normativas dos membros (HONNETH, 2003b, p. 155-157).

$\mathrm{Na}$ concepção de Honneth, o que motivaria indivíduos ou grupos sociais a colocarem em questão a ordem social e se engajarem nas práticas de resistência seria a conviç̧áo moral de que, com relação a suas capacidades ou características sociais, "[...] os princípios de reconhecimento considerados legítimos foram aplicados de maneira incorreta ou inadequada". Como consequência do anterior, uma experiência moral que possa ser descrita como uma experiência de desrespeito deve ser vista como o fundamento motivacional de todos os conflitos sociais ${ }^{15}$ : grupos sociais ou sujeitos se consideram desrespeitados ou náo reconhecidos em determinados aspectos de suas características ou capacidades como consequência da convicção de que a "[...] prática institucional de um princípio de reconhecimento legítimo falhou de maneira injustificada em refletir suas disposiçóes" (HONNETH, 2003b, p. 157).

Nesse sentido, Honneth propóe uma teoria da justiça baseada em três pilares. Essa proposta teórica resulta das consideraçóes colocadas pelo autor quando sustenta que os sujeitos nas sociedades modernas dependem, para a formação das suas identidades, de três formas de reconhecimento social com base nos princípios normativos anteriormente descritos: amor, tratamento jurídico equitativo e estima social (HONNETH, 2003b, p. 180).

Na visão de Honneth, uma teoria da justiça deve incorporar os três princípios normativos, que de forma conjunta podem ser entendidos como princípios de reconhecimento. Como forma de poder fazer uso da sua autonomia, afirma o autor, os indivíduos devem poder ser reconhecidos de certa maneira

15 Neste ponto a crítica principal é dirigida a Fraser. 
em suas necessidades, em sua igualdade jurídica e em suas contribuições sociais de acordo com o tipo de relação social em questão. $\mathrm{O}$ que pode ser chamado de "justo", nesta formulação, é estimado em cada caso, devendo ser considerados os diferentes tipos de relaçóes entre os indivíduos: "[...] se o que está em questão é uma relação moldada pelo apelo ao amor, então o princípio de necessidade tem prioridade; em relaçóes modeladas pela lei, o princípio de igualdade tem primazia; e em relaçóes cooperativas, o princípio do mérito prevalece (HONNETH, 2003b, p. 181).

Honneth conclui sua análise sobre a concepção de justiça, afirmando:

[...] the tripartite division I propose arise neither form mere agreement with the empirical results of research on justice, nor from a social-ontological distinction between patterns of social relations, but rather from reflection in the historical conditions of personal identityformation. Because we live in a social order in which individuals owe the possibility of an intact identity to affective care, legal equality, and social esteem, it seems to me appropriate, in the name of individual autonomy, to make the three corresponding recognition principles the normative core of a conception of social justice. (2003b, p. 181-182).

\section{À guisa de conclusão}

Como colocávamos no início do texto, a política da diferença e a teoria do reconhecimento têm se tornado uma perspectiva omnipresente nas ciências sociais contemporâneas. A mudança do foco do problema da desigualdade social para as questóes da diferença e do reconhecimento tem levantado assuntos de importância fundamental para uma política de questionamento da ordem social.

Charles Taylor tem enfatizado que o não reconhecimento é um aspecto fundamental na perpetuação do processo de subordinação social de determinados grupos. A contribuição do autor canadense tem sido importante para defender um liberalismo político que promova direitos universais, no entanto regatando a importância das identidades sociais e de sua preservação.

Honneth, por sua vez, também tem destacado que as injustiças distributivas devem ser entendidas como expressôes institucionais de desrespeito social ou como expressão de relaçóes de reconhecimento injustificadas. E que o problema decisivo a ser colocado é a justificação normativa das demandas de reconhecimento. Dessa forma, Honneth problematiza os pressupostos de uma 
teoria da justiça, um dos temas dominantes da teoria e filosofia política nas décadas de 1980 e 1990, defendendo que os princípios de amor, tratamento jurídico equitativo e estima social devem ser fundamentais para uma teoria normativa na construção de uma sociedade justa.

A análise de Fraser, por sua vez, tenta conciliar a teoria do reconhecimento com os aspectos materiais da desigualdade social. Fraser busca harmonizar as preocupaçóes mais clássicas da análise das desigualdades sociais com as novas perspectivas colocadas pelos movimentos identitários. Entretanto, alguns autores têm destacado que o resultado dessa tentativa teria sido a construçáo de um sistema teórico dual que náo conseguiria entender de forma adequada as inter-relaçóes entre os elementos materiais e culturais ou simbólicos da dominação social.

A questáo central que tem colocado o debate entre Honneth e Fraser é entender que tipo de relação existe entre reconhecimento e redistribuição, entre classe e status e entre os aspectos econômicos e culturais da dominação social no capitalismo. E, neste ponto, a questão fundamental é, como afirma Markell (2008, p. 459), entender o funcionamento da economia política como sistema de integraçáo social das sociedades contemporâneas.

Nesse sentido, uma das críticas, particularmente dirigida a Fraser, coloca a atenção nas conexôes causais estabelecidas entre cultura e identidade, por uma parte, e economia política, por outra. Iris Young (1997), por exemplo, critica a estrutura teórica proposta por Fraser e seu sistema conceitual "dual".

Para Young, a proposta colocada por Fraser de recuperar a dimensáo econômica da dominação social construindo uma dicotomia entre redistribuição e reconhecimento fracassa na forma de sua construção conceitual. Uma solução teórica mais apropriada, afirma Young, seria conceitualizar questóes de justiça envolvendo reconhecimento e identidade considerando seus fundamentos e resultados materiais, mas sem serem redutíveis à dinâmica do mercado ou à exploraçáo econômica. Para a autora, seria importante recuperar a forma como, por exemplo, os estudos culturais de inspiração marxista pensaram essa relação; a economia política é atravessada pela cultura e a cultura tem uma clara dimensão material também. O aporte dos estudos culturais é ter chamado a atenção aos efeitos que a cultura tem no processo de produção e reproduçáo econômica e na reproduçáo das relaçóes de classe no capitalismo (YOUNG, 1997, p. 154). 
Para Young, uma forma de superar essa polarização de redistribuição versus reconhecimento é elaborar uma proposta conceitual que estabeleça as mediaçóes entre questóes simbólicas e discursivas e suas consequências do ponto de vista da organizaçáo social do trabalho e de acesso aos recursos materiais. Uma melhor solução do ponto de vista teórico, afirma Young, é pluralizar os conceitos de injustiça e opressão de forma que a cultura seja uma das dimensóes de luta na interaçáo social com os outros grupos e indivíduos (YOUNG, 1997, p. 160 $)^{16}$.

Judith Butler também tem formulado algumas considerações importantes sobre o tipo de relação adequada entre questóes materiais e culturais e como consequência entre redistribuiçáo e reconhecimento. Butler retoma as formulaçôes de Marx, desenvolvidas no texto Formaçôes Econômicas Pré-capitalistas, no qual explica a forma como a cultura e a economia se constituíram como esferas separadas, e analisa como o processo de institucionalizaçáo da economia como uma esfera separada é consequência de uma operação de abstração iniciada pelo próprio capital. Na leitura de Marx, esse processo de distinçáo em diferentes esferas da estrutura social é efeito e culminação da divisão social do trabalho (BUTLER, 1998, p. 42).

Como afirma Markel (2008), esse processo de emergência da economia como esfera separada através de uma operaçáo de abstraçáo operada pelo capital revela um processo complexo e contraditório na forma como as diferentes esferas da estrutura social se relacionam e condicionam no interior do capitalismo. Para o autor, essa lógica revela a contradição no interior da forma social do capital. Por um lado, essas formas envolvem, de fato, uma separaçáo entre a esfera da economia e a esfera da cultura; por outro, a forma em que esse processo de separaçáo se produz também explicita uma continuidade entre formas "econômicas" e formas "culturais"; isto é resultado da forma como, no capitalismo, ocorre o processo de valorização, que abstrai o valor de troca do valor de uso das mercadorias. Se o dualismo colocado por Fraser - e em certo sentido isso também é verdadeiro para a análise de Honneth - nos permite uma reflexão das práticas sociais, seja do ponto de vista da redistribuição, seja do ponto de vista do reconhecimento, esse dualismo também pode expressar a realidade de um processo de diferenciação social que se constrói sob a dicotomia redistribuição versus reconhecimento, mas -

16 Sobre esta questão, ver: Young, 1990. 
continuando com o argumento de Markell - cuja dicotomia aparece como expressão de uma contradição mais profunda no interior da vida social moderna (MARKELL, 2008, p. 461-462).

Se, como afirma Markel, o processo de reconhecimento no capitalismo é, por definição, contraditório, como resultado desta lógica de abstração, então, o processo de reconhecimento social - como analisado por Taylor, Fraser e Honneth - está sujeito ao possível fracasso como consequência da lógica de abstração colocada pelo capitalismo. E se esta análise estiver correta, pelo menos algumas das desigualdades sistemáticas e das hierarquias sociais características da vida econômica contemporânea podem ser entendidas como resultado das perspectivas existenciais do sujeito moderno no imaginário capitalista. A partir da análise proposta, e concordando com a conclusão colocada por Markel, abrem-se novas possibilidades para problematizar a questáo do reconhecimento e do tipo de relação mais adequada com a redistribuição, e também se oferecem novas formas de pensar a distinção entre ambos os conceitos que deverão ser explorados de forma a superar uma aparentemente falsa dicotomia real e conceitual (MARKELL, 2008, p. 462).

\section{Referências}

ACKERMAN, B. Social Justice in the Liberal State. Yale University Press: New Haven, 1980 .

BENHABIB, S. Critique, norm, and utopia. A study of the foundations of critical theory. New York: Columbia University Press, 1986.

BENSAIID, D. Marx, o intempestivo. Grandeza e misérias de uma aventura crítica (séculos XIX e XX). Rio de Janeiro: Civilização Brasileira, 2000.

BENSAÏD, D. Lenin, ou a política de tempo partido. In: BENSAID, D.; LÖWY, M. Marxismo, modernidade e utopia. São Paulo: Xamã, 2000. p. 177-191.

BENSAIID, D. Os irredutíveis: teoremas da resistência para o tempo presente. São Paulo: Boitempo, 2008.

BENSAÏD, D. Elogio de la política profana. Barcelona: Ediciones Península, 2009.

BOURDIEU, P. et al. The Weight of the World: Social Suffering in Contemporary Society. Stanford: Stanford University Press, 1999. 
BUTLER, J. Merely Cultural. New Left Review, n. 227, p. 33-44, jan./feb. 1998.

Problemas de gênero. Feminismo e subversão da identidade. Rio de Janeiro: Civilização Brasileira, 2014.

.; LACLAU, E.; ŽIŽEK, S. Contingencia, hegemonía, universalidad. Diálogos contemporáneos en la izquierda. Buenos Aires: Fondo de Cultura Económica, 2011.

COOLE, D. Is Class a Difference that Makes a Difference. Radical Philosophy, n. 77, p. 1-19, 1996.

DWORKIN, R. Levando os direitos a sério. São Paulo: Martins Fontes, 2007.

FRASER, N. "From Redistribution to Recognition? Dilemmas of Justice in a 'Post-Socialist' Age”. New Left Review, n. 212, p. 68-93, july/aug. 1995a.

- "Recognition or redistribution? A Critical reading of Iris Young's Justice and the Politics of Difference”. Journal of Political Philosophy, v. 3, n. 2, p. 166-180, 1995 b.

Justice interruptus: Critical reflections on the "postsocialist" condition. New York: Routledge, 1997.

. Heterosexism, Misrecognition and Capitalism: A Response to Judith Butler. New Left Review, n. 228, p. 140-149, mar./apr. 1998.

Rethink Recognition: Overcoming Displacement and Reification in Cultural Politics. New Left Review, n. 3, p. 107-120, may/june 2000.

Social Justice in the Age of Identity Politics: Redistribution, Recognition, and Participation. In: .; HONNETH, A. Redistribution or Recognition? A politicalphilosophical Exchange. London-New York: Verso, 2003a. p. 7-109.

Distorted Beyond All Recognition: A Rejoinder to Axel Honneth. In:

HONNETH, A. Redistribution or Recognition? A political-philosophical Exchange. London-New York: Verso, 2003b. p. 198-236.

Feminism, Capitalism and the Cunning of History. New Left Review, n. 56, p. 97-117, mar./apr. 2009.

.; HONNETH, A. Introduction. In: Redistribution or Recognition? A political-philosophical Exchange. London-New York: Verso, 2003. p. 1-5.

GORZ, A. Metamorfoses do trabalho: Crítica da razão econômica. São Paulo: Annablume, 2003. 
HONNETH, A. Teoria crítica. In: GIDDENS, A.; TURNER, J. (Org.). Teoria social hoje. São Paulo: UNESP, 1999. p. 503-552.

Luta por reconhecimento: a gramática moral dos conflitos sociais. Tradução de Luiz Repa. São Paulo: Editora 34, $2003 a$.

Redistribution as Recognition: A Response to Nancy Fraser”. In: FRASER, N.; HONNETH. Redistribution or Recognition? A political-philosophical Exchange. LondonNew York: Verso, 2003b. p. 110-197.

The Point of Recognition: A Rejoinder to the Rejoinder”. In: FRASER, N. HONNETH,. Redistribution or Recognition? A political-philosophical Exchange. LondonNew York: Verso, 2003c. p. 237-267.

JAY, M. A imaginaçáo dialética: História da Escola de Frankfurt e do Instituto de Pesquisas Sociais (1923-1950). Rio de Janeiro: Contraponto, 2008.

KEUCHEYAN, R. The Left Hemisphere. Mapping Critical Theory Today. Londres; Nova Iorque: Verso, 2013.

KYMLICKA, W. Multicultural Citizenship: A liberal Theory of Minority Rights. Oxford: Oxford University Press, 1995.

Contemporary Political Philosophy. An Introduction. Oxford: Oxford University Press, 2002.

LUXEMBURGO, R. Reforma social ou revolução? (Com um anexo: milícia e militarismo). In: _. Textos escolhidos. Volume I (1899-1914). São Paulo: Editora da Unesp, 2011. p. $1-112$.

MARKELL, P. Recongnition and Redistribution. In: DRYZEK, J.; HONIG, B.; PHILLIPS, A. The Oxford Handbook of Political Theory. Oxford: Oxford University Press, 2008. p. $450-469$.

MELO, R. Teoria crítica e os sentidos da emancipação. São Paulo, 2012, mimeo.

PHILLIPS, A. From Inequality to Difference: A Severe Case of Displacement. New Left Review, n. 224, p. 143-153, july/aug. 1997.

RAWLS, J. [1971]. Uma teoria da justiça. São Paulo: Martins Fontes, 2008. Justice as Fairness: Political Not Metaphysical. Philosophy and Public Affairs, v. 14, n. 3, p. 223-251, 1985.

SALIH, S. Judith Butler e a teoria queer. Belo Horizonte; São Paulo: Autêntica, 2012. 
SAFATLE, V. Para um conceito anti-predicativo de reconhecimento. Revista Lua Nova, v. 1, p. 79-117, 2015.

TAYLOR, C. As fontes do Self. São Paulo: Ediçóes Loyola, 1997.

A política do reconhecimento. In:

Argumentos filosóficos. São Paulo:

Ediçóes Loyola, 2000. p. 241-274.

et al. 1994. Multiculturalism and the "Politics of Recognition". Princeton:

Princeton University Press, 1994.

TORFING, J. New Theories of Discourse. Oxford: Blackwell, 1999.

TRILLING, L. Sincerity and Autenticity, Cambridge: Harvard University Press, 1972.

YOUNG, I. M. Justice and the Politics of Difference. Princeton: Princeton University Press, 1990.

Unruly Categories: A Critique of Nancy Fraser's Dual Systems Theory. New Left Review, n. 222, p. 147-160, may/apr. 1997.

\section{Identity, Recognition and Redistribution: a critical analysis of Charles Taylor, Axel Honneth and Nancy Fraser's theories}

\section{Abstract}

The politics of identity and the idea of recognition have become dominant issues in contemporary political theory. Recognition, as a concept, means that an individual or a social group claims the right to have their identity recognized, directly or throw the mediation of set of institutions. The theories that have evaluated these questions address both important theoretical issues and central political subjects, as the definition of minority rights, national self-determination claims or the challenges posed of our increasingly multicultural societies. The main objective of this paper is to discuss the central arguments presents by Charles Taylor, Axel Honneth and Nancy Fraser emphasizing the discussion around the relationship between recognition and redistribution. A more specific purpose is to analyze the relation between the question of injustice based on the demand of identity and the problem of economic inequality. Finally, we try to understand some of the theoretical and political implications of the idea of difference and the recognition theory in a broader conceptual perspective.

Keywords: Identity. Recognition. Redistribution. Taylor. Honneth. Fraser.

Recebido em: 13/07/2016 Aceito em: 14/01/2017 